Revista Complutense de Historia de América

ISSN: $1132-8312$

http://dx.doi.org/10.5209/RCHA.56735

\title{
Sandino en La Habana: la VI Conferencia Internacional Americana a ojos de la prensa e intelectualidad españolas ${ }^{1}$
}

\author{
Manuel Andrés García ${ }^{2}$
}

Recibido: 8 de octubre de 2015 / Aceptado: 13 de febrero de 2016

Resumen. El objetivo de este artículo es la revisión de las polémicas suscitadas en la VI Conferencia Internacional Americana (La Habana, 1928) como consecuencia de la presencia militar estadounidense en Nicaragua. Partiendo de un análisis sobre los acontecimientos que derivaron en dicha intrusión, abordaremos la naturaleza del movimiento panamericanista como instrumento de la diplomacia de Washington respecto a sus vecinos del sur, así como la resistencia de éstos al intervencionismo de los Estados Unidos. Para ello utilizaremos el seguimiento que de dicha reunión hizo la intelectualidad y prensa hispanoparlante de la época y, en particular, la española.

Palabras clave: Antiimperialismo; panamericanismo; relaciones España-América Latina; Augusto César Sandino; Nicaragua; siglo XX.

\section{[en] Sandino in Havana: The VI International American Conference in the Eyes of the Spanish Press and Intellectuals}

\begin{abstract}
The aim of this article is to review the polemics arising from the VI International American Conference (Havana, 1928) as a result of the presence of the U.S. military in Nicaragua. Starting with an analysis of the events which derived from said intrusion, we will look at the nature of the Panamerican movement as an instrument of Washington's diplomacy with the United States' southern neighbours, as well as the resistance of the latter to U.S. intervention. To do this we will use the commentary made at that time about the aforementioned conference by the Spanish-language Press and intellectuals, especially the Spanish ones.

Keywords: Anti-imperialism; Panamericanism; Latin American-Spanish relations; Augusto César Sandino; Nicaragua; 20th Century.

Sumario. 1. Introducción. 2. Bases doctrinales para una expansión: del primer panamericanismo al supremacismo rooseveltiano. 3. La expansión norteamericana tras el Corolario Roosevelt. El caso de Nicaragua. 4. La VI Conferencia Internacional Americana vista desde España. 5. Conclusiones. 6. Referencias bibliográficas.
\end{abstract}

Cómo citar: Andrés García, M. (2017) Sandino en La Habana: la VI Conferencia Internacional Americana a ojos de la prensa e intelectualidad españolas, en Revista Complutense de Historia de América 43, 285-306.

\footnotetext{
Este trabajo forma parte del proyecto $\mathrm{I}+\mathrm{D}+\mathrm{i}$ “Donde la política no alcanza. El reto de diplomáticos, cónsules y agentes culturales en la renovación de las relaciones entre España e Iberoamérica" (HAR2014-59250-R), financiado por el Ministerio de Economía y Competitividad en la convocatoria de 2014.

2 Universidad de Huelva (España)

E-mail: manuel.andres.dhis2@uhu.es
} 


\section{Introducción}

La Habana fue la primera capital latinoamericana en contar con la presencia de un presidente estadounidense durante la celebración de una conferencia panamericana. No era éste un acontecimiento menor. Prácticamente desde finales del XIX la política exterior norteamericana había hecho de la hegemonía continental uno de sus objetivos, ya fuese por la fuerza o por otros medios.

La Guerra de Secesión (1861-1865) y la posterior Reconstrucción (1865-1877) supusieron un antes y un después a este respecto. Superados el conflicto que desangró al país durante cuatro largos años y el periodo en el que se intentó, con desigual éxito, restañar las heridas producidas por la confrontación, el gobierno de Washington procuró un cambio de táctica geopolítica enfocado a desplazar a sus competidores europeos -y, en particular, a Gran Bretaña- del que consideraba su espacio natural de influencia.

La rivalidad entre británicos y estadounidenses comenzaría prácticamente desde las independencias de las antiguas colonias ibéricas. No en vano una de las primeras decisiones de las nuevas repúblicas fue, por lo general, buscar el reconocimiento de Londres y la correspondiente firma de tratados comerciales con sus autoridades, a fin de garantizar la irreversibilidad de la nueva situación. Fue así como los intereses anglosajones lograrían, desde un principio, ventajas y privilegios que sólo podían jugar en detrimento del resto de potencias interesadas en el comercio con América. $\mathrm{Y}$ es desde tal enfoque que conviene analizar un teorema como la Doctrina Monroe: por un lado, como manifestación de la voluntad estadounidense de oponerse a toda pretensión colonialista europea en territorio americano; por otro, como germen doctrinal desde el que se armonizarían -con los subsiguientes añadidos ${ }^{3}$ - los principios políticos fundacionales de las Trece Colonias con las ambiciosas expectativas comerciales de su economía y una tendencia expansionista que pronto demostraría no tener nada que envidiar al imperialismo europeo.

Las urgencias estadounidenses tuvieron mucho que ver con la paulatina caída de su comercio exterior. Era este uno de los pilares fundamentales de su economía, lo que no había impedido una debacle continuada desde mediados de siglo que tendría una de sus máximas expresiones en sus relaciones con América Latina. Así, si en 1880 las importaciones de productos latinoamericanos ascendían a 176 millones de dólares, las exportaciones a dicho mercado apenas llegaban a los 58. La crisis también tendría su reflejo en las actividades de su flota mercante, que pasó de transportar el $50 \%$ del tonelaje salido de sus puertos en 1850 al $17 \%$ en $1900^{4}$.

Tal coyuntura hizo que comenzase a ganar terreno en Washington la necesidad de reorientar la política exterior hacia un objetivo un tanto genérico -cobrar un mayor protagonismo internacional- pero con una lectura claramente "doméstica": relegar, por no decir ahuyentar, a las potencias europeas del ámbito comercial latinoamericano. Fue así como comenzó a implementarse una política que encontraría sus fundamentos en los postulados del panamericanismo. Y fue así como un discurso en principio destinado al fomento de las relaciones interamericanas, acabaría confrontando los distintos intereses para dirimir el predominio estadounidense en el continente.

\footnotetext{
3 Nos referimos a dogmas como la Doctrina del Destino Manifiesto (Manifest Destiny) -por la que se asumiría el sino estadounidense de expandirse del Atlántico al Pacífico- o a enmiendas como el Corolario Roosevelt, por el que la Doctrina Monroe pasaría a asimilarse en su perspectiva más agresiva y arbitraria.

$4 \quad$ Smith, 1991: 78.
} 
Partiendo de este punto es que nos proponemos como objetivo revisar el seguimiento que haría la prensa e intelectualidad españolas de una reunión política de alto nivel -la VI Conferencia Internacional Americana- marcada por un acontecimiento trascendente para la opinión pública latinoamericana, como sería la incapacidad estadounidense para imponerse en Nicaragua a la guerrilla de Augusto César Sandino. Y, del mismo modo, contrastar el debate generado en dicha reunión entre los partidarios de frenar definitiva y legalmente las injerencias norteamericanas al sur de sus fronteras y los partidarios de no alterar dicha situación.

\section{Bases doctrinales para una expansión: del primer panamericanismo al supremacismo rooseveltiano}

Uno de los primeros prohombres del panamericanismo fue James G. Blaine, secretario de Estado en dos gabinetes distintos -con James A. Garfield (1861) y Benjamin Harrison (1889-1893)- Blaine fue el impulsor de la que sería la primera gran asamblea panamericanista: la I Conferencia Internacional Americana, celebrada en Washington del 2 de octubre de 1889 al 19 de abril de 1890 .

No puede decirse que la Conferencia colmase las expectativas de Blaine, pero tampoco cabría calificarla como un fracaso. En realidad ya su celebración habría que estimarla positivamente, vistos los muchos obstáculos con que se encontraron. Las diferencias existentes entre los países invitados, por ejemplo, no garantizarían la asistencia de todas las delegaciones; del mismo modo, tampoco podían desdeñarse las presiones europeas para malograr la cita. Y todo ello por no mencionar las divergencias existentes dentro de la clase política estadounidense respecto a la necesidad de la reunión ${ }^{5}$.

Dos fueron los temas principales del Congreso: en el plano económico, la viabilidad de una unión aduanera entre los países allí representados; en el diplomático, la posible articulación de un sistema de arbitraje que solventase los futuros desacuerdos entre los respectivos gobiernos. Sin embargo en ambas cuestiones se hicieron ostensibles, para sorpresa de los anfitriones, los recelos de las delegaciones invitadas. Un recelo que sólo podía extrañar a los estadounidenses -ciegos ante el contraste de intereses inherente a ambas propuestas- $\mathrm{y}$ que se vería avivado con algunas mociones norteamericanas que traslucirían sus intenciones hegemónicas.

Ninguno de los delegados latinoamericanos ignoraba el perjuicio que una zona comercial exclusivamente americana produciría a las relaciones con Europa y sus inversiones; inversiones y relaciones de las que, por otra parte, no todos estaban dispuestos a prescindir. Argentina, por ejemplo, había consolidado su modelo agroexportador gracias a una Europa ávida de sus productos, elevando a sus grupos de poder a unos niveles de opulencia inéditos. Por lógica, la posibilidad de que Buenos Aires dificultase los contactos con quienes le habían otorgado semejante bonanza era más que lejana. Sin embargo la oposición argentina tendría un sesgo más allá de lo económico, entre otros motivos porque el potencial productivo del país -durante décadas, uno de los principales emporios trigueros del mundo- auspiciaría entre su

Las posturas enfrentadas en un asunto como la unión comercial ilustraría lo dicho, con una facción demócrata partidaria de la misma y un bando republicano casi siempre opuesto a tal posibilidad. Maya Sotomayor, 1996: 765-766. 
clase política unas prospectivas más dirigidas a disputar con Washington el liderazgo continental que a someterse dócilmente a sus dictados ${ }^{6}$, iniciando una rivalidad dentro del panamericanismo que perduraría prácticamente hasta mediados del $\mathrm{XX}^{7}$.

En lo concerniente al resto de delegaciones, la cuestión de la unión aduanera fue recibida con una ambivalencia que resultaría fatal para las intenciones de Blaine. El previsible daño que un descenso de las inversiones europeas podía ocasionar a las respectivas economías sería ya, de por sí, un elemento determinante para entender dicha ambigüedad. Pero a éste hubo que sumarle otro factor de peso: la posibilidad, muy real, de una intervención armada por parte de los hasta entonces inversores. La legación venezolana, por citar un caso, tenía sólidos motivos para la desconfianza tras la reciente crisis vivida con Londres a cuenta de la frontera guyanesa ${ }^{8}$. Del mismo modo, el resto de delegaciones tenían fresco el recuerdo de cómo los esfuerzos estadounidenses por intermediar en dicha crisis habían sido baldíos.

No le irían mejor las cosas a Blaine en cuanto a sus deseos de un arbitraje interamericano. Pese a las buenas palabras de los organizadores respecto a su nula intención de convertirse en juez de las disputas continentales', las suspicacias estuvieron a la orden del día en este asunto. Las posturas quedarían claramente confrontadas conforme fue avanzando el debate: a un lado, Estados Unidos, partidario de un sistema de arbitraje obligatorio y con un tribunal permanente cuya sede se preveía en Washington; al otro, unas repúblicas latinoamericanas reacias a comprometer su soberanía en beneficio de un órgano cuyo control se adivinaba en manos estadounidenses. Fue así como las propuestas en pos de un sistema de arbitraje más moderado se convertirían en el banderín de enganche de las distintas delegaciones. Argentina, nuevamente, se destaparía como una de las principales valedoras de esta vía aunque, en realidad, la oposición al proyecto sería mayoritaria, haciéndose patente en los discursos de portavoces como el bonaerense Manuel Quintana, el chileno Emilio C. Varas o el guatemalteco Fernando Cruz.

Al final, la Conferencia cumplió los pronósticos del mexicano Matías Romero en sus prolegómenos respecto a la ausencia de resultados prácticos ${ }^{10}$. Un presagio más

Todavía en 1919 un supuesto viejo diccionario español describiría una Argentina capaz de rivalizar en el futuro con los Estados Unidos. Polak, 2005: 26.

7 La rivalidad entre Argentina y Estados Unidos fue visible más allá del panamericanismo. La Doctrina Drago, por ejemplo, emitida en 1902 tras la negativa de Washington a intervenir activamente contra el bloqueo naval a que era sometida Venezuela por sus acreedores europeos, fue una respuesta directa del ejecutivo porteño contra todo tipo de intervencionismo pero, indirectamente, también de la aplicación subjetiva que de la Doctrina Monroe hacía el gobierno norteamericano. A partir de entonces las relaciones entre ambos países pasarían por diversos picos de tensión visibles en las reuniones panamericanistas. Así, si en la celebrada en Río, en 1906, pareció instalarse un clima de cordialidad, el posterior apoyo estadounidense a un Brasil en plena carrera armamentística con su vecino del sur volvería a enquistar las posturas. Algo parecido ocurriría en la de Buenos Aires, en 1910, donde el buen ambiente reinante contrastó con la negativa del gobierno argentino a suscribir una propuesta brasileña de adhesión regional a la Doctrina Monroe. Para un mayor conocimiento sobre los vaivenes de esta relación es muy recomendable la lectura de Cisneros - Escudé, 2000, concretamente el tomo VIII.

8 Una crisis que ya venía de lejos tras el rechazo venezolano a la Línea Schomburgk como límite fronterizo con la Guayana Británica. Fue la posibilidad de un enfrentamiento con los británicos la que llevó al gobierno de Caracas a pedir, en 1884, ayuda al Departamento de Estado, pero ésta no pasaría de un ofrecimiento de mediación que, además, fue rechazado inicialmente por Londres.

9 Ese fue el sesgo de la circular enviada el 29 de noviembre de 1881 -siendo Blaine Secretario de Estado- por la que se les animaría a concurrir a la futura Conferencia. Y así lo recordaría el representante chileno, Emilio C. Varas, en la sesión del 14 de abril, citando textualmente los términos de dicha circular en: Acta n ${ }^{\circ} 65$. Sesión del 14 de Abril de 1890 en U.S. Government, 1890: 718.

10 Maya Sotomayor, 1996: 770. 
que previsible teniendo en cuenta el carácter meramente consultivo de la reunión. Empero no puede desdeñarse su importancia como primera manifestación del nuevo estilo diplomático norteamericano $\mathrm{o}$, dicho de otro modo, del cambio de estrategia adoptado por Washington respecto a América Latina. No es casualidad que la actual Organización de Estados Americanos ubique su origen en dicha reunión, ya que uno de los escasos acuerdos que tendría plasmación a corto plazo sería la creación de la Unión Internacional de las Repúblicas Americanas, asociación destinada en principio a recopilar información económica a través de la Oficina Comercial de las Repúblicas Americanas. Del mismo modo, tampoco sería fortuito que dicha Oficina tuviese su sede en Washington DC, ni que su supervisión quedase en manos del Secretario de Estado estadounidense.

Las siguientes reuniones panamericanistas no harían sino constatar el gradual predominio norteamericano y la decreciente oposición de los países latinoamericanos. La Oficina Comercial de las Repúblicas Americanas pasaría a convertirse, en 1902, en Oficina Internacional de las Repúblicas Americanas; y la política exterior de Washington a dar trazas de una ambición creciente. Ya la Guerra HispanoEstadounidense sería un aldabonazo de sus intenciones, despertando la alarma de un amplio sector de la intelectualidad hispanoamericana y de determinados grupos de poder que coligieron de lo acontecido en Cuba un punto de inflexión en la hegemonía continental. No obstante, los sucesivos acontecimientos y la progresión del influjo estadounidense parecieron precipitar a los gobiernos latinoamericanos -pese a la desigual resistencia por evitarlo- hacia una lenta pendiente de dependencia tan disímil como irremisible.

Una panorámica en paralelo de los avances del panamericanismo en este periodo y las intervenciones militares estadounidenses -si no sincrónicas, sí correlativasilustraría a la perfección, aun sin entrar en detalles, el gradual proceso de supremacía al que hacemos referencia. Mucho tuvo que ver en ello la radicalización del discurso expansionista norteamericano y su plasmación, de facto, por parte de William McKinley y, sobre todo, de Theodore Roosevelt y Elihu Root.

Root fue y es considerado por muchos como el arquitecto del panamericanismo y la cara amable de una política exterior aparentemente condescendiente pero, en realidad, implacable. Su estilo quedaría de manifiesto con las negociaciones llevadas a cabo para regular las relaciones de las antiguas colonias españolas con los Estados Unidos. Entre sus iniciativas más conocidas estuvieron el devolver Cuba a los cubanos; la eliminación de los aranceles a los productos de importación puertorriqueños o la aprobación de un estatuto para las Filipinas con el que garantizar un gobierno libre y la protección de las costumbres locales. Sin embargo, la consecución de tan loables propósitos encubriría un envés turbio: en el caso cubano, una Enmienda Platt que dejaría a la Isla supeditada a los intereses estadounidenses so pena de intervención militar ${ }^{11}$; en el puertorriqueño, el desdén hacia la oposición interna con decisiones de carácter soberano ciertamente discutibles ${ }^{12}$; en el filipino, el encubrimiento de

La subordinación política de la Isla llegaría a un extremo que -aun tras la derogación de dicha enmienda- no hubo decisión o acontecimiento político trascendente en Cuba que no contase previamente con la aquiescencia de la embajada estadounidense. Andrés García, 2014: 603.

12 Así podemos calificar todo lo que fue la organización legislativa e institucional puertorriqueña tras el Desastre del 98. Por otra parte, tanto el nombramiento del gobernador como el de los Secretarios de Estado, Tesorería y Contraloría de la isla quedarían en manos del presidente de los Estados Unidos, debiendo ser sancionados por el Senado. Rodríguez Díaz, 2006: 45. 
la guerra sucia contra los patriotas del archipiélago ${ }^{13}$.

La vertiente diplomática de Root maquillaría la mucho más beligerante y taxativa de Roosevelt; un Roosevelt que conjugaría en su gobierno el convencimiento respecto al sino estadounidense de prevalecimiento y su deber de llevar el progreso y la civilización a todos aquellos países incapaces de hacerlo por sí mismos. Ambas directrices deben ser contempladas desde una perspectiva de superioridad racial ya presente en los escritos rooseveltianos previos a su carrera política. Nos referimos a obras como Hunting trips of a Ranchman (1885) o Ranch life and the hunting trail (1888), en las que el enaltecimiento del norteamericano blanco vendría acompañado de una exaltación del medio ambiente de su país para asimilar a los distintos grupos raciales, así como de su certidumbre en cuanto a la decadencia de los indígenas americanos ${ }^{14}$. Semejante enfoque estaría en línea con los parámetros del darwinismo social, muy presentes en los círculos intelectuales de la época y visor desde el que se contemplaría, por parte de Occidente, las relaciones a sostener por las grandes potencias con el resto de territorios.

Roosevelt aunaría en su pensamiento la darwinista asignación de virtudes/taras según fenotipo -muy cercana a la taxonomía que establecería entre razas y formas de gobierno- y una particular reivindicación de la eficiencia y la moralidad como sustrato del carácter, ya fuese como individuos o como colectivo ${ }^{15}$. Esta visión le llevaría a entablar una correlación muy al uso con el triunfante positivismo; una analogía en la que el ser norteamericano -siempre entendiendo como tal el norteamericano blancosería identificado con la civilización, quedando para el resto de pueblos al sur de sus fronteras una concepción de barbarie que, no obstante, quedaría graduada conforme a factores como su desarrollo económico, político y cultural ${ }^{16}$.

Tal distinción explicaría la distinta vara de medir utilizada por los Estados Unidos en sus relaciones con las repúblicas latinoamericanas, sobre todo tras el Corolario Roosevelt, que transformaría la antaño defensora Doctrina Monroe en un alegato con el que priorizar los intereses estadounidenses en el continente y respaldar toda acción pertinente en pro de su protección. Así, la percepción de Argentina, Brasil o Chile como países lo suficientemente avanzados como para no precisar de tutela ajena explicaría la ausencia de injerencias armadas en dichos territorios; del mismo modo, la apreciación de los estados centroamericanos como caóticos -o semibárbaros, en consonancia con el discurso- los ubicaría en la categoría figurada de "países precisados de una mano firme para su progreso", convirtiendo a la región en un espacio en el que Washington haría confluir las maniobras de su diplomacia con las intervenciones de su ejército ${ }^{17}$.

Kramer, 2006: 143-148.

Dyer, 1992: 8-9.

Jeffers, 1998: 20 y 44.

Castro Peña, 2007: 97

Una buena referencia para conocer la evolución diplomática norteamericana por modelos como la conocida Doctrina del Big Stick, de Teddy Roosevelt, hasta la Diplomacia del Dólar propugnada por William Taft o la clásica Diplomacia del Cañonero sería Ryan, 2000. 


\section{La expansión norteamericana tras el Corolario Roosevelt. El caso de Nica- ragua}

La idea de una América Central necesitada de un mentor firme caló con fuerza en aquellos sectores políticos estadounidenses convencidos de que el desarrollo de su país pasaba por la preponderancia exterior. No puede decirse que fuera éste un convencimiento de inicio -es más, algunas de las intervenciones en el extranjero contaron, en principio, con una importante oposición interna- pero tampoco es exagerado afirmar que, tras el periodo Roosevelt, la posición de Washington en cuanto a sus relaciones externas era de predominio.

Las incorporaciones a costa de España no serían sino el prólogo de una estrategia no centrada tanto en lo territorial como en el control de otras economías foráneas y la sumisión de sus gobernantes; una estrategia que pasaría también por dejar claro a Europa que no aceptaría más injerencias por su parte al sur de sus fronteras. No es que con ello los intereses europeos quedasen desasistidos -al menos en lo que a sus acreedores se refiere, Estados Unidos siempre procuró el pago de las deudas contraídas- pero sí se verían privados de la opción militar como factor de presión, quedando dicha alternativa en las exclusivas manos de Washington. Las consecuencias no tardarían en hacerse notar, multiplicándose las actuaciones militares estadounidenses en Centroamérica y el Caribe en las siguientes décadas. Muchas de estas intervenciones estuvieron estrechamente ligadas a los intereses de las grandes corporaciones, convirtiendo a los marines en el brazo armado de sus intereses ${ }^{18}$. Lo cierto es que, si hiciésemos una relación de todas las acciones y ocupaciones estadounidenses en la región el resultado sería elocuente ${ }^{19}$. Lo mismo si observamos el incremento de las inversiones directas de los Estados Unidos en el continente entre los años 1898 y $1929^{20}$.

El interés de los Estados Unidos por Nicaragua ya venía de antiguo. No en vano fue ésta su primera opción para la construcción de un canal ístmico. Sin embargo, la deriva política nicaragüense generaría luchas internas por el poder cuyo resultado haría tambalear el predominio de las potencias foráneas en la región. Fue José Santos Zelaya, triunfador de la Revolución Liberal, quien personificaría dicho peligro con el planteamiento de proyectos políticos de carácter interregional y su oposición a satisfacer los intereses foráneos en detrimento de los propios. Tal proceder vino marcado por una concepción autónoma y personalista del poder opuesta a la nueva dinámica expansionista que parecía confirmarse en la zona. Conforme a ello fue que Zelaya prestó ayuda a los liberales hondureños en su lucha contra el gobierno conservador

18 Smedley D. Butler, prestigioso oficial del Cuerpo de Marines, publicaría tras su jubilación algunos de los escritos más incisivos del antiintervencionismo estadounidense. Entre los más conocidos destaca el editado en noviembre de 1935 por la revista Common Sense, en la que llegaría a hacer un paralelismo entre lo que había sido su historial militar y el delictivo de Al Capone: "Looking back on it, I feel I might have given Al Capone a few hints. The best he could do was to operate his racket in three city districts. We Marines operated on three continents". Butler, 1935: 8-12.

19 Hasta comienzos de los años 30 padecieron dichas intervenciones Cuba (1898-1902, 1906-1909, 1912 , 1917 1922); Guatemala (1920); Haití (1915-1934); Honduras (1903, 1907, 1911, 1912, 1924, 1925); México (1914, 1917); Nicaragua (1909-1910, 1912-1925, 1926-1933); Panamá (1903); Puerto Rico (1898) y República Dominicana (1903, 1904, 1905, 1912, 1916-1924). Martí, 2004: 31.

20 En 1897 la inversión en América Central era de 11,5 millones de dólares y de 304,3 en toda América Latina. En 1929, de 201,7 en Centro América y de 3645,8 en todo el continente. En todo caso el porcentaje centroamericano sobre el total giraría en todo momento entre el 5 y el 7\%. Torres Rivas, 1969: 144. 
de Domingo Vázquez; una ayuda que provocaría la deposición y sustitución de éste por el liberal Policarpo Bonilla. Y conforme a ello también firmó, en 1895, el Pacto de Amapala, una iniciativa para impulsar una nueva federación centroamericana y que, en principio, firmaron el propio Bonilla, Zelaya y el salvadoreño Rafael Antonio Gutiérrez. El proyecto llegaría a tener una constitución, aprobada el 27 de agosto de 1898, por la que se proclamó la creación de los Estados Unidos de Centroamérica; empero apenas sobreviviría unos meses a su promulgación, ya que el 13 de noviembre de ese mismo año un golpe de Estado en El Salvador instalaría a Tomás Regalado en el poder, comunicando ese mismo mes su salida de la nueva federación. La falta de respuesta de sus socios haría el resto.

Las pretensiones de Zelaya también tendrían su reflejo en el ámbito económico, pero los diversos planes que esbozaría para modernizar el país serían un continuo choque entre el deseo y lo posible. Si bien intentó hacer del café el puntal fundamental de la economía nicaragüense, la realidad haría que tuviese que adoptar criterios más propios del conservadurismo, como la creación de monopolios en sectores como la minería o la concesión a empresas extranjeras de diversos derechos de explotación. Fue así como entraron en el país varias compañías norteamericanas respaldadas por un Departamento de Estado decididamente a favor de su expansión en la región. No obstante, la entrada de los intereses estadounidenses -al igual que las fluctuaciones económicas nicaragüenses durante este periodo- estuvieron marcadas por la prospectiva de un canal ístmico que nunca llegaría a construirse y que, sin embargo, le procuraría a Zelaya la animadversión británica y norteamericana ${ }^{21}$.

Las tensiones entre Zelaya y los Estados Unidos irían en aumento conforme fue consolidándose la influencia del segundo en la zona. Nicaragua, por su potencial, pretendía ejercer un liderazgo sobre sus vecinas que Estados Unidos no se podía permitir. Esto haría que las distintas aventuras políticas y militares de Zelaya -dirigidas a imponer en su entorno gobiernos de sesgo liberal- fuesen contempladas con desconfianza desde Washington, sobre todo tras el fracaso de los acuerdos diplomáticos de $1902^{22}$. Ni siquiera el impulso estadounidense de un nuevo acuerdo en la región llevaría la tranquilidad a sus promotore ${ }^{23}$ lo que, en cierto modo, marcaría el destino de Zelaya. Así, el desencuentro del mandatario con la empresa maderera Emery ${ }^{24}$ serviría como trasfondo de un levantamiento, en octubre de 1909, que aunaría a la oposición interior -personalizada en la alianza entre el liberal Juan José Estrada y el conservador Emiliano Chamorro- con el exilio político y el apoyo norteamericano.

${ }_{21}$ La primera, por incorporar la Mosquitia a Nicaragua a fin de controlar la cuenca del río San Juan, fundamental en caso de querer construir allí el canal. La segunda, por la firme decisión de Zelaya de no ceder la soberanía de territorio alguno en caso de ser Nicaragua la ruta escogida para el paso interoceánico, lo que haría subir enteros a la opción panameña.

22 Nos referimos al Tratado de Paz y Arbitraje Obligatorio Centroamericano o Pacto de Corinto, suscrito por Nicaragua, El Salvador, Honduras y Costa Rica. Éste se vería vulnerado en 1907 con el conflicto que enfrentaría a Nicaragua con Honduras y El Salvador a cuenta de las acciones de los exiliados de uno y otro bando y que terminaría con la derrota de la alianza hondureño-salvadoreña en Namasigüe.

23 El Tratado General de Paz y Amistad Centroamericano, firmado el 20 de diciembre de 1907 por Guatemala, Nicaragua, Honduras, Costa Rica y El Salvador en el marco de la Conferencia de Paz Centroamericana.

24 El Congreso nicaragüense le revocaría la concesión en 1904 por no cumplir distintos compromisos forestales y ferroviarios adquiridos a raíz del acuerdo. También se le acusaría de vender ilegalmente insumos destinados a otros propósitos y, por tanto, no gravados fiscalmente. Tras la revocación la empresa pidió ayuda a su gobierno, que exigiría al de Managua la devolución de la concesión o una compensación de dos millones de dólares. Tras diversas negociaciones, la indemnización quedaría fijada en 600.000 dólares a pagar en cuotas anuales de 50.000 . 
Sin intrusiones foráneas el enfrentamiento habría sido una guerra civil de resultado incierto, pero la actuación de Estados Unidos resultaría determinante para el desenlace del conflicto, sobre todo tras la Nota Knox.

La Nota Knox se produjo a raíz del apresamiento de dos ciudadanos norteamericanos -Lee Roy Cannon y Leonard Groce- tras intentar volar una lancha con soldados del gobierno. Puestos a disposición de la justicia militar, ambos serían fusilados el 16 de noviembre de 1909 pese a la petición de clemencia. Fue entonces cuando el Departamento de Estado -en voz de su Secretario, Philander Chase Knox- remitiría una carta al embajador nicaragüense, Felipe Rodríguez Mayorga, en la que rompería relaciones con el gobierno de Zelaya y reconocería la legitimidad de los rebeldes. La misiva, fechada el 1 de diciembre, fue tan taxativa que, pese a admitirse en ella la condición militar de los fusilados, la prensa estadounidense la consideró prácticamente el preludio de una declaración de guerra, obligando al mandatario a dimitir, el 22 de diciembre, para partir acto seguido hacia el exilio.

La política nicaragüense, tras Zelaya, viviría un profundo cambio. Su sucesor, José Madriz Rodríguez, apenas pudo sostener unos meses la lucha contra los rebeldes, llegando finalmente a la presidencia Estrada. Mucho tuvo que ver en ello Thomas G. Dawson quien, enviado por el Departamento de Estado como agente especial, maniobró entre bambalinas hasta lograr que los sublevados aceptasen todas y cada una de sus condiciones; entre ellas, la solicitud de un empréstito a banqueros norteamericanos ${ }^{25}$. Fue ahí donde, enterados de los planes de Washington, entraría en juego la Brown Bross \& Company, presentando credenciales para hacerse cargo de la concesión de dicho empréstito. Pese a que las condiciones impuestas por Dawson finalmente vieron la luz para escándalo de propios y ajenos, lo cierto es que la entrada de esta compañía en Nicaragua acabaría, con el tiempo, poniendo las finanzas del país en sus manos ${ }^{26}$. Con todo, tampoco Estrada se perpetuaría en la presidencia ya que, en mayo de 1911, sería expulsado del país por sus aliados tomando el poder Adolfo Díaz Recinos, como presidente, y Luis Mena como ministro de Guerra.

El ascenso de Díaz a la presidencia abriría un nuevo tiempo definido por la primacía del bando conservador; las disputas internas por el poder; la relegación de los li-

25 El resto de requisitos fueron la elección de una Asamblea Constituyente que confirmaría a Estrada como presidente y a Díaz Recinos como vicepresidente, aprobaría una nueva Constitución y aboliría determinadas concesiones hechas por Zelaya a no norteamericanos. Aparte, se exigió la creación de una comisión mixta de reclamaciones, el castigo de los responsables de la ejecución de Cannon y Groce y la eliminación de los zelayistas de la Administración. Selser, 1984: 39.

26 Tan así sería que Nicaragua llegaría a ser denominada en determinados medios como "la república de los hermanos Brown". Adolfo Díaz resultaría capital en todo ello. Merece la pena transcribir un texto de Gregorio Selser en el que narra su papel en el empréstito solicitado a los hermanos Brown: "Adolfo Díaz era un empleado de mil dólares al año en La Luz y Los Ángeles Mining Co., propiedad de la familia Fletcher por la cual velaba solícito el secretario de Estado Knox. Su primera medida fue autorizar a Salvador Castrillo, su encargado de negocios en Washington, a celebrar un tratado por medio del cual los Estados Unidos acordaban un empréstito de 15 millones de dólares, al 90\% de emisión, fuera de gastos, con un interés del 5\% y un 1\% como amortización. Como garantía ofrecía la entrega de los ferrocarriles y vapores nacionales. Como la propuesta había sido en realidad preparada por el Departamento de Estado, y no hubo tiempo o no se quiso que lo hubiera escrito para su traducción, fue presentado al Congreso de Nicaragua escrito en idioma inglés, con orden terminante del plenipotenciario Weitzel de que se aprobara sin quitarle un punto ni hacerle variaciones a las comas. Seis diputados y dos secretarios de Gobierno, que presumiblemente conocían el inglés y que "no quisieron mancharse con la nota de vendedores de su patria" se negaron a suscribir el Tratado, sin poder evitar empero que fuera sancionado. Pero lo que no produjo la falta de sensibilidad de los diputados lo provocó el prurito legalista del Senado de la Unión; por tres veces y a pesar de la especial recomendación del presidente Taft, se negó a ratificar el tratado Knox-Castrillo, que quedó así sin vigor”. Selser, 1984: 41. Ver también Quijano, 1987: $202-203$. 
berales como alternativa, supeditados a secundar opciones ajenas; y la confirmación de Washington como árbitro de la situación. Todo este compendio confluirá en episodios como la Revolución Libero-Conservadora de 1912, en la que la sustitución de Mena por Emiliano Chamorro como ministro de Defensa abrió la caja de los truenos enfilando al país hacia una nueva guerra civil. Las diferencias entre los conservadores se harían patentes entre un Mena designado por la Asamblea Constituyente para ocupar la presidencia y un Adolfo Díaz remiso a dejar el poder y dispuesto a aliarse con Chamorro para mantenerlo; a la par, la nueva coyuntura liberal quedaría personificada en uno de sus líderes, Benjamín Zeledón, quien puso su prestigio al servicio de Mena; en cuanto al papel decisorio de los Estados Unidos, quedaría patente con la petición de ayuda militar a Washington por parte de Díaz, siendo definitivo para la victoria final.

La derrota y exilio de Mena, junto a la muerte de Zeledón, trajo consigo la consolidación de un régimen conservador completamente sumiso a las directrices norteamericanas. Ni siquiera las desavenencias internas entre conservadores cuestionarían este último extremo, al punto que los estadounidenses pudieron permitirse dejar un contingente militar permanente en el país, hasta 1925, como si de un protectorado se tratase. Apenas eran 400 hombres, pero su sola presencia haría patente quién tenía la última palabra dentro de Nicaragua.

Durante estos años, los Estados Unidos obtuvieron todo lo que pudieron desear del gobierno de Managua, como el Tratado Bryan-Chamorro, firmado en 1914, por el que se les concedió a perpetuidad -a cambio de tres millones de dólares- los derechos de construcción de un canal interoceánico en territorio nicaragüense, al igual que los derechos por 99 años, renovables por otros tantos, para construir una base militar en el golfo de Fonseca y el arriendo, por el mismo tiempo y en iguales condiciones, de las islas del Maíz para su protección ${ }^{27}$.

La dependencia política del país llegaría a tal punto que, tras la salida de los marines, bastó una nueva crisis para que retornasen. En esta ocasión fue por el ascenso a la presidencia del conservador Carlos Solorzano, en enero de 1925, con el liberal Juan Bautista Sacasa como vicepresidente. La presencia de un liberal en el gobierno provocó reacciones inesperadas de determinados segmentos del conservadurismo nicaragüense, como el levantamiento encabezado por Emiliano Chamorro que provocaría la dimisión de Solorzano en enero de 1926 pero no su consolidación en la presidencia, siendo obligado por Washington a entregar nuevamente el poder a Adolfo Díaz en noviembre de ese año. El problema vino cuando los liberales se negaron a aceptar que Sacasa quedase fuera del nuevo gobierno, estallando una nueva conflagración entre liberales y conservadores -la Guerra Constitucionalista- agravada con la llegada de un nuevo destacamento norteamericano a petición de Díaz.

Como en el pasado, la intervención estadounidense volvería a ser decisiva. De poco servirían los intentos de Sacasa por ser reconocido como presidente o los triunfos de José María Moncada como jefe militar del anterior: el primero, por mucho eco que quisiera alcanzar en el exterior, poco podía hacer sin la aquiescencia estadounidense, claramente favorable a Díaz; y el segundo comprobaría desde su desembarco -y, sobre todo, tras su primera victoria- la predisposición de los marines a favor del

Nada que no se hubiese exigido a Panamá en 1903, incluyendo el reconocimiento de la soberanía estadounidense en estos territorios durante el periodo de arriendo, concesión y de posibles renovaciones. 
gobierno $^{28}$. Una actitud que se vería refrendada el 7 de febrero de 1927 cuando las tropas conservadoras atacaron Chinandega con el apoyo activo de aviones norteamericanos.

Las injerencias estadounidenses no terminarían ahí, aumentando la presión tanto por vía diplomática -con el envío de Henry L. Stimson para intermediar entre los bandos y conseguir un acuerdo- como militar, tras anunciarse oficialmente el envío de una flota de 16 barcos al mando de Julian Latimer. Fruto de todo ello sería el Pacto del Espino Negro, suscrito en Tipitapa el 7 de mayo de 1927 por Moncada pero no por Sacasa quien, sintiéndose traicionado por el primero, abandonó el país junto a sus colaboradores. Conforme a dicho pacto ambos bandos debían proceder a su desarme y se permitiría al presidente Díaz terminar su mandato, quedando las fuerzas estadounidenses en el país para garantizar que se cumpliese lo suscrito. No obstante, uno de los principales dirigentes del bando liberal se negaría a aceptar el trato y anunció su intención de proseguir con las hostilidades mientras las tropas norteamericanas permanecieran en Nicaragua. Su nombre era Augusto César Sandino y, en apenas medio año, había pasado de ser un completo desconocido a comandar la resistencia liberal en Las Segovias. Pocos meses después, tras rechazar el pacto, su nombre resonaba a ambos lados del océano por sostener exitosamente la resistencia contra los marines y hacer del conflicto nicaragüense una cuestión de trascendencia internacional que tendría su eco en la VI Conferencia Internacional Americana o Conferencia Panamericana de La Habana.

\section{La VI Conferencia Internacional Americana vista desde España}

Que el expansionismo norteamericano se impusiese de facto en América Latina no significó que no fuese contestado desde las tribunas extranjeras. En el caso europeo, España sería uno de los países en los que con mayor acritud se censuraría la dinámica expansionista estadounidense. Frescas estaban las huellas del 98 como para obviar los errores y abusos del responsable, con lo que toda resistencia a los dictados de Washington encontraría su correspondiente resonancia en la prensa española. Sandino no sería una excepción, de manera que, conforme su fama fue creciendo, mayor sería el seguimiento que se daría a sus acciones y más numerosas las informaciones y opiniones en torno a los acontecimientos nicaragüenses. Con una ventaja añadida: la indagación que desde los medios peninsulares se haría a los principales comentarios y polémicas apuntados en el extranjero sobre Nicaragua ${ }^{29}$.

La dinámica política española tampoco sería ajena a la resonancia que tales críticas alcanzarían en la prensa nacional. Cierto es que en las primeras décadas del XX los intereses españoles parecieron desplazarse de América al norte de África y Europa. Sin embargo, la llegada al poder de Primo de Rivera revitalizaría las tesis de quienes propugnaban el hispanoamericanismo como vía para revitalizar, aun parcialmente, la imagen de España en el exterior ${ }^{30}$. Ya la Gran Guerra fue considerada por

28 Esto aconteció alrededor del 26 de noviembre de ese año cuando, tras derrotar a las tropas del gobierno, los marines forzaron un alto el fuego y procedieron al desarme de los rebeldes. Selser, 2001: 445.

29 Una internacionalización vinculada no tanto a la capacidad de la prensa española para derivar corresponsales como de su dependencia, a este respecto, de las agencias de noticias extranjeras y otras publicaciones foráneas.

30 El hispanoamericanismo ha sido largamente tratado dentro de la historiografía española. Una magnífica obra sobre dicha doctrina y sus implicaciones es Sepúlveda, 2005. También son recomendables para entender el rol 
muchos una oportunidad perdida para recuperar cierta presencia en el continente, sobre todo en el plano comercial ${ }^{31}$. Empero el declinante influjo español en sus antiguas colonias quedaría todavía más de manifiesto en episodios como el frustrado intento de obtener un puesto permanente en el Consejo de la Sociedad de Naciones. Fue éste un objetivo para el que se quiso hacer valer, por parte española, su supuesta condición de portavoz de las naciones hispanoamericanas. Sin embargo, tal rol quedaría en entredicho al negarse una de ellas, Brasil, a secundar la candidatura. Motivo: las legítimas aspiraciones del gobierno brasilero a ocupar el mismo espacio pretendido por Madrid. De este modo, aunque España logró su reelección como miembro no permanente, quedo patente, por una parte, su falta de apoyos internacionales para objetivos de alto calado y, por otra, el contraste entre la imagen que el gobierno español creía proyectar de sí en América y una realidad que limitaba sensiblemente su crédito en las cancillerías latinoamericanas.

La coyuntura no parecía estar a favor de las pretensiones de una España no siempre presta a aprovechar la ocasión ni predispuesta a asumir, en el marco hispanoamericano, un papel exento de protagonismo. Con todo, achacar la declinante influencia española en la región a la indecisión o a la falta de perspectiva política no dejaría de ser un ejercicio de ingenuidad. Entre otras razones porque uno de los principales obstáculos a enfrentar, en pro de recobrar el ascendiente perdido, sería la voluntad hegemónica estadounidense en un escenario que consideraba preferente para sus intereses. Y es en la confluencia de todos estos factores donde se hacen comprensibles los esfuerzos de Madrid por generar mayor empatía con las repúblicas hispanoamericanas ${ }^{32}$, el reforzamiento de su aparato diplomático en el continente -sobre todo durante el Directorio ${ }^{33}$ así como las frecuentes críticas que la prensa española dedicaría al expansionismo norteamericano. Una prensa, por otra parte, sometida a censura por el gobierno militar, lo que explicaría -con los correspondientes matices ${ }^{34}$ - las escasas divergencias entre los medios a la hora de reprobar los manejos estadounidenses en Latinoamérica ${ }^{35}$.

de esta ideología en la América Hispana el trabajo de Granados, 2005 o, para el caso colombiano, el de Gracia Pérez, 2011.

31 Pereira Castañares ya señalaría en un viejo artículo cómo el comercio entre España y sus antiguas colonias creció cuantitativamente durante el conflicto, pero no de manera sostenida -por consolidada-y sí en unos porcentajes muy inferiores a los mantenidos con Francia, Gran Bretaña y los Estados Unidos. Prueba de ello sería que tras la conflagración, entre 1916 y 1920, la América Hispana apenas representaría para el sector comercial español el $15{ }^{\prime} 4 \%$ de sus exportaciones y el 14'4\% de sus importaciones. Pereira, 1986: 138.

32 Durante la década de los 20 -y en particular bajo el primorriverismo- se haría muy habitual la organización de eventos, exposiciones y congresos con el objeto de acercar posturas entre España y sus antiguas colonias. Entre ellos ocuparían un lugar preferente el vuelo del Plus Ultra, en 1926, y la Exposición Iberoamericana de Sevilla, celebrada en 1929.

33 En ese periodo se incrementaría el número de legaciones y representantes en la América Hispana en un $20 \%$. También se incrementó el número de cónsules, pasando de 276 en 1923 a 291 en 1930, elevando de categoría algunos de los consulados, sobre todo en Argentina, Cuba, México y Chile. Este crecimiento iría en paralelo al de los presupuestos de las agencias diplomáticas y consulares, pasando las primeras del 13\% del total dispuesto por el Ministerio en 1915 a un 28\% en 1930; y las segundas un similar 28\% del total dispuesto por el gobierno a tal efecto. Pereira, 1986: 152.

34 En el caso de los periódicos consultados este trabajo no son equiparables un diario liberal de corte conservador como El Imparcial con el periódico El Sol -liberal pero de tendencia más progresista y regeneracionista- o el más cercano a la izquierda obrera de los analizados, La Libertad. Del mismo modo tampoco tendría el mismo

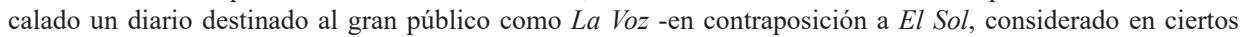
ambientes como elitista- con otros más implicados con la oposición a la Dictadura, aun de manera solapada, como el Heraldo de Madrid. Este último, tras la caída del Directorio, acabaría convirtiéndose en uno de los principales voceros del republicanismo de izquierdas.

35 Para tener un conocimiento más exhaustivo sobre las relaciones hispanoamericanas de este periodo son 
Tal cúmulo de circunstancias, unido a la ya citada dependencia de los medios españoles en lo que a la información exterior se refiere, explica la naturaleza y características de lo editado en las cabeceras nacionales. O que las noticias en torno a lo que acontecía al sur de Río Grande -y, para el caso, en Nicaragua- aunasen con frecuencia en sí la censura al intervencionismo yanqui con la repercusión que tales acontecimientos tenían en los ámbitos político y mediático europeos, latinoamericanos e, incluso, estadounidenses.

El diario madrileño $\mathrm{El} \mathrm{Sol}$, por ejemplo, podía recopilar en una misma columna -bajo el significativo epígrafe "Imperialismo Norteamericano"- las críticas periodísticas londinenses al intervencionismo de los Estados Unidos; la reclamación de impresiones del Senado argentino a su gobierno por los sucesos nicaragüenses; la incredulidad de la prensa centroamericana por el menosprecio de Washington hacia la resistencia sandinista;... y el anuncio del posible viaje de Coolidge a La Habana para asistir al Congreso de la Unidad Panamericana, lo que -para los círculos liberales británicos- acentuaría "el carácter imperialista del panamericanismo"36.

Los prolegómenos de la Conferencia estuvieron condicionados, al igual que la reunión en sí, por las elecciones presidenciales estadounidenses, previstas para noviembre de ese mismo año. Tal circunstancia haría que los demócratas atacasen al republicano Coolidge a través de los asuntos más polémicos de su administración, siendo Nicaragua uno de ellos tras trastocarse el desprecio inicial hacia Sandino en una guerra cada vez más exigente en hombres y recursos. Apenas unos días antes del comienzo de la reunión el diario $L a V o z$ pregonaba el acento electoral del conflicto nicaragüense con un revelador encabezamiento -"Nicaragua se convierte en una cuestión de propaganda electoral"- inserto en un apartado de nominación no menos taxativa: "El Imperialismo Americano" ${ }^{37}$. No obstante, dentro de dicha columna resaltaría una noticia particularmente interesante: el anuncio de una propuesta conjunta de varias repúblicas americanas para sacar a colación en La Habana el problema de Nicaragua. El anuncio no podía ser más inoportuno teniendo en cuenta el agrio debate suscitado en el Senado a cuenta de la intervención y del que se haría eco la prensa extranjera ${ }^{38}$. Ni tampoco pudo ser más imprudente la respuesta de Washington a través de su Secretario de Exteriores, Frank B. Kellog, quien descartaría tal posibilidad por estar fuera de programa surtiendo de argumentos a los críticos del panamericanismo. Eduardo Gómez de Baquero, periodista liberal de corte moderado, subrayaría el sarcasmo de que en La Habana pudieran discutirse los proyectos aprobados en 1927 en la Conferencia de Jurisconsultos de Río de Janeiro pero se obviase Nicaragua y la vulneración del principio de no intervención acordado en dicho encuentro ${ }^{39}$. Del mismo modo Augusto Barcia, futuro ministro con Azaña, re-

recomendables trabajos ya clásicos como Pereira - Cervantes, 1992. Más reciente, y a fin de cobrar una visión más general del actuar diplomático español en los dos últimos siglos, véase Pereira, 2009.

36 El Sol, año XI, no 3144, 28-VII-1927, 9.

37 La Voz, año IX, no 2254, 7-I-1928, 5.

38 "El debate en el Senado ha sido particularmente adverso a Coolidge. El senador Wheelar insistió en que la intervención viola claramente los preceptos constitucionales norteamericanos. El senador Begg defendió al Gobierno, diciendo que Norteamérica necesita intervenir en Nicaragua para evitar que Inglaterra se apodere de la zona del Canal. El corresponsal del "Times" en Washington dice que el argumento es de una futilidad y de una pobreza visibles". La Voz, año IX, n 2254, 7-I-1928, 5.

39 "Sería un sarcasmo que mientras la Conferencia de la [sic] Habana discute los proyectos de Ríojaneiro [sic] en 1927, en uno de los cuales proyectos se consagra el principio de no intervención, cerrarse los ojos y los oídos para no ver ni oír lo que pasa en Nicaragua, e ignorara oficialmente el hecho flagrante del atropello de aquel 
memoraría mordazmente los votos de no intromisión hechos más de veinte años antes por Root ${ }^{40}$ ante la nueva cita panamericana: "Colombia, Haití, Santo Domingo y Nicaragua pueden decir hasta qué punto se cumplieron los votos de Root. Verdad es que el orador no dijo cómo habían de marchar las Repúblicas débiles y menos afortunadas al lado de las fuertes y afortunadas. ¡Y un modo de marchar al lado es el del encadenamiento!" 41.

La presencia de Coolidge marcaría el acto de inauguración, haciendo éste un hábil discurso conciliador en el que reivindicaría la solidaridad panamericana. Sin embargo, los medios internacionales recogerían su intervención en términos claramente desfavorables. La prensa británica, ausente la cuestión nicaragüense en el discurso, acogió la soflama con evidente desinterés. La italiana, por el contrario, sería mucho más incisiva, con comentarios como los de Tribuna -que describiría la reunión como "tan estéril e inútil como las precedentes"- o los del fascista Il Tevere, que tacharía la política exterior de Washington de hipócrita por disfrazar invasiones armadas como operaciones para restaurar el orden, advirtiendo -con jocosa ambivalencia- cómo "pronto tendrá Europa que mostrarse prudente, porque, si somos sospechosos de turbulencias, veremos en el horizonte la estela de humo de grandes acorazados conduciendo soldados para restaurar el orden en Europa" ${ }^{42}$. Con todo, fue la prensa hispanoamericana la que con mayor dureza reaccionó ante el discurso. El Sol aglutinaría las principales críticas a la alocución de Coolidge, resaltando su carácter meramente protocolario y cómo, pese a los esfuerzos del orador por esquivar el espinoso tema nicaragüense, éste no había dejado de estar presente en el ambiente ${ }^{43}$.

Las disensiones en torno a los principios de soberanía y de no intervención iban a ocupar un lugar principal en las conversaciones, lo que no garantizaba posibles acuerdos. Las discrepancias se harían notorias incluso en detalles como la ovación con que fueron recibidas las enseñas de Nicaragua y México al ser trasladadas, junto a las restantes, al salón de sesiones. También la rumorología se haría notar, con murmuraciones sobre posibles propuestas de Argentina, México, Santo Domingo y Haití que, aun desde perspectivas distintas, pretendían impedir que los Estados Unidos actuasen libremente más allá de sus fronteras. Igualmente, también se comentó una probable proposición del representante norteamericano, Charles Evans Hughes, para "reafirmar el derecho de protectorado de los Estados Unidos en dirección al Sur, hacia el cabo de Hornos" 44 .

principio. A las repúblicas hispanoamericanas no se les puede exigir que se tapen los oídos para no escuchar el eco de la fusilería de Nicaragua, ni que se venden los ojos para no ver la dramática lucha entre el gigante y el pigmeo. Sería pedir demasiado a su espíritu panamericano”. El Sol, año XII, n 3256, 10-I-1928, 1.

40 Concretamente en la III Conferencia Panamericana de Río de Janeiro, celebrada en 1906, donde -en palabras de Barcia- testimonió lo siguiente: "No queremos obtener victoria alguna; no deseamos más territorio que el nuestro, ni más soberanía que la soberanía sobre nosotros mismos. Consideramos la independencia y la igualdad de derechos de los menores y más débiles miembros de la familia de las naciones con derecho a tantos respetos como los grandes Imperios, y consideramos la observancia de dicho respeto como la principal garantía de los débiles contra la opresión de los fuertes". La Libertad, año X, nº 2436, 11-I-1928, 1.

41 Ibídem.

42 El Sol, año XII, nº 3263, 18-I-1928, 7.

43 "Todos los diarios de Hispanoamérica publican comentarios al discurso del Presidente Coolidge. Varios periódicos acusan al Presidente Coolidge de no haber pronunciado durante su discurso nada más que generalidades y frases oscuras, no teniendo el valor de plantear la cuestión de Nicaragua, y respecto a esta cuestión hacen un llamamiento a todos los países diciéndoles que lo que hoy le ocurre a Nicaragua puede muy bien mañana pasarle a cualquier otro país". Ibidem.

44 Ibídem. 
La delegación norteamericana optó por una táctica de perfil bajo, aceptando puestos secundarios dentro de las distintas comisiones y ninguna de sus presidencias. Una actitud que vendría acompañada de actos paralelos a la Conferencia en la que se buscó justificar la política estadounidense desde el respeto a la independencia de los estados y su integridad territorial. Significativa fue, a este respecto, la intervención de Hughes en el banquete dedicado a su delegación por la Cámara de Comercio Norteamericana de La Habana ${ }^{45}$. No obstante, la condescendencia duró lo que tardaron en plantearse proposiciones contrarias a sus intereses. Una de las más señeras fue la propuesta de la delegación mexicana para que la Dirección General de la Unión Panamericana fuese por turno, lo que sería agriamente replicado por Hughes, empeñado en que el puesto fuese ejercido de manera permanente por un alto funcionario norteamericano ${ }^{46}$.

Lo mismo ocurriría en el debate generado en torno a los derechos de navegación aérea, presentando la delegación estadounidense un proyecto para asegurarse su control en la zona del Canal y su derecho a suscribir nuevos tratados con cualquier país americano en el que los signatarios -es decir, Estados Unidos y el estado en cuestión- demarcasen las rutas permitidas a la aviación civil y las reservadas para uso militar o gubernamental. No sería éste un asunto menor, ya que -tal como temían muchos de los presentes- su aprobación conllevaría el control absoluto de Panamá y Guantánamo y, de manera indirecta, el control sobre las rutas comerciales aéreas centroamericanas.

Pese a que algunas propuestas pudieron contrariar a Hughes y su equipo, lo cierto es que en ningún momento pareció que la delegación americana perdiese el control de la reunión. Opinantes hubo, como Luis de Zulueta, que acertarían en su diagnóstico al describir tres circunstancias ilustrativas del porqué de tal situación, y que podríamos resumir en tres factores interconectados: la tradicional desunión latinoamericana, plasmada en una resistencia retórica, más que de facto; por la contraposición de intereses entre los asistentes y la incuestionable habilidad estadounidense para manejar ambas circunstancias en su provecho:

A unos el hacer y a otros el decir, es una gentil división del trabajo. Bien que se forme un ambiente verbal contrario al imperialismo yanqui; bien que se aclamen con frenéticos aplausos las banderas de Méjico y Nicaragua. A la hora de decidir y de acordar ya procurará Norteamérica ganar las votaciones. Por de pronto, según los cablegramas recientes, la propuesta de Méjico, del Méjico aclamado, se rechazó por diez y nueve votos contra uno.

$[\ldots]$

Claro está que en el fondo, moralmente, no produce la Conferencia la impresión de una asamblea de veinte o veintitantas naciones diversas, separadas, que van a debatir sus complejos problemas, sino la de dos grandes agrupaciones, dos fuerzas históricas, dos Américas, que tratan de entenderse y armonizarse: los Estados Uni-

$45 \quad$ El Imparcial recogería algunos extractos de su discurso: "Estamos actualmente en Nicaragua, pero lo que allí hacemos y la línea de conducta que allí observamos obedece a las insistentes gestiones hechas por los dos partidos en pugna y por el interés de la paz, del orden y de la legalidad de las elecciones.

No abrigamos el menor deseo de quedarnos allí. Deseamos que Nicaragua sea un pueblo fuerte, próspero e independiente. Hemos ido a Nicaragua para hacer frente a una necesidad urgente e imperiosa, pero temporal, y de allí nos retiraremos tan pronto como esto sea posible". El Imparcial, año LXII, no 21127, 24-I-1928, 8.

46 Heraldo de Madrid, año XXXIII, n 33101, 25-I-1928, 1. 
dos del Norte y los Estados desunidos del Centro y del Sur.

$[\ldots]$

El norteamericano necesita hallar hacia el Sur mercados, explotaciones industriales, factorías. Para comerciar regularmente le hace falta que esas naciones gocen de todos los bienes [...] Pero no le hace falta, de igual suerte, que gocen de absoluta independencia, de libre soberanía, de plena personalidad y cultura espiritual ${ }^{47}$.

El análisis de Zulueta podía estimarse certero visto el control que Estados Unidos mantendría en las votaciones aparentemente más espinosas. Si en la propuesta mexicana las diferencias fueron tan notables a su favor, no lo serían menos en la que presentaría el argentino Honorio Pueyrredón para introducir una declaración favorable a la reducción arancelaria que, en esos momentos, Washington no estaba dispuesta a suscribir. No obstante, contraviniendo parcialmente lo expuesto por Zulueta, si bien Estados Unidos pudo soslayar que se abriese un debate literal sobre lo que estaba aconteciendo en Nicaragua, no pudo hacerlo respecto al principio de no intervención acordado en Río, siendo en dicha discusión donde surgirían los mayores enconos pero, también, las diferencias existentes entre delegaciones latinoamericanas.

La disputa se empezó a plantear tras la presentación de los anteproyectos preparados en Río como base para un corpus de Derecho Internacional con el que, de común acuerdo, regular las relaciones entre los gobiernos americanos. Fue ahí donde el principio de no intervención cobraría una relevancia previsible, abriendo una brecha insalvable entre aquellas delegaciones que aceptarían cierta ambigüedad terminológica en el documento y las que, por el contrario, exigirían una claridad diáfana en la conceptualización del principio y su aplicación. El porqué de tal exigencia lo expresaría a la perfección el mexicano Aquiles Elorduy:

[...] en esta Conferencia hay dos grupos de naciones: las naciones de mayor poder y las de menos poder. ¿De qué manera se puede tener la confianza absoluta que el ilustrado doctor Maúrtua, [principal ponente del texto] desea que se tenga por las naciones al aceptar las declaraciones básicas? De una sola manera: que esas declaraciones sean de tal manera redactadas que las naciones débiles se vean por ellas amparadas. Para las naciones fuertes las declaraciones casi no tienen importancia, si no es desde el punto de vista de que las débiles acepten lo que aquellas consideran importante e interesante desarrollar para la política del Continente americano ${ }^{48}$.

Algunas de las críticas, como la del salvadoreño José Gustavo Guerrero, recalcarían la incongruencia de la ponencia al obviar, en su parte principal, lo discutido en Río, haciendo hincapié en el contrasentido de que su principal valedor, el peruano Víctor Maúrtua, hubiese secundado en la capital carioca lo que no presentaba en La Habana:

El doctor Maúrtua, nos ha dicho que los trabajos realizados en Río eran completamente inaceptables. Esta mañana me permití leer varias partes de los procesos verbales de aquellas reuniones, y ahora vuelvo yo a preguntar al doctor Maúrtua, por qué fue que con aire de triunfo hizo notar que había unanimidad en el voto recaído sobre el deber de la no intervención, propuesto por el doctor Anderson de

47 El Sol, año XII, n 3279, 5-II-1928, 1.

48 Diario de la VI Conferencia Internacional Americana, nº 34, 18-II-1928, 495. 
Costa Rica. No comprendo cómo en Río aceptó lo que ahora está repudiando, y justamente en el instante en que el esfuerzo de aquellos jurisconsultos iba a ser coronado por el éxito ${ }^{49}$.

Partidarios de las tesis de Guerrero fueron, entre otros, Pueyrredón ${ }^{50}$; el guatemalteco Carlos Salazar ${ }^{51}$; el hondureño Mariano Vázquez o el colombiano Jesús M. Yepes, quien condensaría la importancia del debate en una frase taxativa: "Nosotros vamos en este camino tan lejos como lo requiera la independencia de todos los pueblos de América, porque aspiramos a que el principio de la no-intervención sea la columna principal sobre la que repose el panamericanismo" 52 . Hasta trece de las delegaciones mostrarían sus recelos por un proyecto edulcorado respecto a lo aprobado en Río y falto de contundencia en sus términos ${ }^{53}$. No obstante también surgieron posturas no sólo en apoyo del ponente sino, incluso, del principio de intervención, siendo el cubano Orestes Ferrara uno de los más elocuentes en su defensa:

No podemos no, nosotros los cubanos, sin cometer ingratitudes, execrar en términos absolutos, la intervención, porque a una intervención magnánima, gloriosa en la Historia de la redención de pueblos, debemos, en gran parte, la existencia soberana de esta República de que nos vanagloriamos, lo que con lealtad y sinceridad proclamamos [...]. La palabra "intervención”, que por una sugestión política del momento es puesta al "Índice" en esta reunión, tiene insigne pasado en todas partes $^{54}$.

Una opinión que vendría respaldada por la del propio Hughes quien, tomando la protección de sus connacionales como coartada, haría una defensa cerrada del derecho de su país a inmiscuirse, en determinadas circunstancias, en aquellos países que no pudieran garantizar su seguridad o la de sus propiedades:

La dificultad, si alguna existe en cualquiera de las repúblicas de América, no es la de agresión exterior. Es una dificultad interna si es que una existe. De vez en cuan-

49 Ibídem: 500-501.

50 En una línea argumental coincidente en su trasfondo con la de Elorduy: "La soberanía de los Estados consiste en el derecho absoluto a la entera autonomía interior y a la completa independencia externa. Ese derecho está garantizado en las naciones fuertes por su fuerza, en las débiles por el respeto de las fuertes. Si ese derecho no se consagra y no se practica en forma absoluta, la armonía jurídica internacional no existe. La intervención diplomática o armada permanente o temporaria atenta contra la independencia de los Estados sin que la justifique el deber de proteger el derecho de los nacionales ya que tal derecho no podrían a su vez, ejercitarlos las naciones débiles cuando sus súbditos sufrieran daños por convulsiones en las naciones fuertes". Ibídem: 492.

51 "Si en vez de la vaguedad de las ideas subjetivas, se expresara con claridad, que se trata de "procedimientos ilegales o contra la ley", lo entenderíamos perfectamente. Así, puedo leer como ejemplo, el contenido del artículo primero de las declaraciones que dice así: "Todo Estado tiene el derecho de existir, de proteger y de conservar su existencia, pero este derecho no implica el poder ni justifica la acción del Estado para proteger y conservar su existencia por medio de procedimientos injustos contra Estados inocentes e inofensivos". Lamento que la vaguedad rodee la declaración de principios; y pido una expresión clara y precisa de los conceptos de independencia, soberanía e igualdad jurídica de los Estados". Ibídem: 491.

52 Ibídem: 499.

53 Tampoco ayudaría a Maúrtua mantener el texto prácticamente sin alteraciones pese a haberlo consultado con un buen número de los presentes y constatado su disconformidad. Un despropósito que Guerrero resaltaría atinadamente en su intervención, siendo apoyado por varios de los asistentes como Elorduy o el dominicano Gustavo Díaz. Ibídem: 500-501.

54 Ibídem: 503. 
do surgen situaciones deplorables y que todos lamentamos, en que la soberanía se suspende, en cuyo transcurso no existe gobierno alguno en ciertas regiones y en que, durante un tiempo, dentro de una esfera limitada, no existe la posibilidad de ejercitar las funciones de la soberanía y de la independencia

$[\ldots]$

¿Qué hemos de hacer cuando el gobierno ha desaparecido y los ciudadanos americanos encuentran que sus vidas peligran? ¿Vamos a cruzarnos de brazos y presenciar cómo perecen porque un gobierno, bajo circunstancias ajenas a su albedrío y de las cuales puede no ser responsable, ya no les proporciona una razonable protección?

$[\ldots]$

Pues bien, es un principio de derecho internacional que en tal caso un gobierno se halla plenamente justificado para proceder, a lo que yo llamaría una interposición de carácter temporal con el objeto de proteger las vidas y bienes de sus nacionales. Podría decir que ello no constituye una intervención ${ }^{55}$.

Tal argumento, pese al maquillaje retórico, estaría en consonancia con muchos de los prejuicios solapados en el Corolario Roosevelt en cuanto a la unidireccionalidad de su aplicación o en el sobrentendimiento de una América Central y un Caribe incapaces de garantizar su estabilidad política y, por tanto, siempre al albur de una intervención norteamericana, cuando no de una ocupación militar para tutelar sus procesos políticos.

La falta de consenso obligaría a dejar pendiente la cuestión para una reunión futura lo que, en la práctica, supondría una victoria de Washington al no verse forzada a suscribir un acuerdo que sólo podía depararle trabas a su hegemonía continental. Fue éste un detalle que no se le escaparía a la prensa, sobre todo tras la propuesta de Maúrtua de no discutir los puntos de desacuerdo a fin de que pudiera aprovecharse el tiempo en analizar la cuestión del arbitraje obligatorio:

El Sr. Maurtúa abriga, en efecto, el propósito, y con ello está de acuerdo con los Estados Unidos, de que termine la Conferencia sin que se vuelva a hablar nuevamente de la cuestión de la no intervención, pues con ello se evitaría un posible debate sobre la actuación de los Estados Unidos con respecto a determinadas Repúblicas centroamericanas, ya que la cuestión de la no intervención sin condiciones es precisamente la principal de las que no han sido objeto de acuerdo todavía ${ }^{56}$.

De este modo, aun antes de clausurarse la Conferencia, ya los medios darían por concluida la reunión y empezarían los análisis en torno a lo allí expuesto. Llamaría la atención la renuncia de Pueyrredón a la jefatura de su delegación y a su cargo como embajador en Washington por discrepancias con su gobierno, pero lo cierto es que cuando ésta se produjo ya había cierto consenso en los medios respecto al éxito estadounidense en La Habana. Uno de los más rotundos a este respecto sería Camilo Barcia Trelles quien, desde las páginas de La Libertad, describiría la Conferencia como una gran decepción ${ }^{57}$. En parecidos términos se expresaría Jorge A. Mitre,

Diario de la VI Conferencia Internacional Americana, no 35, 19-II-1928, 537.

El Sol, año XII, no $3287,15-$ II-1928, 5.

57 " [...] la cosecha no ha correspondido a las esperanzas cifradas: fue pobre, tanto que para la causa de la 
director del periódico argentino La Nación, al ser entrevistado durante una estancia en París ${ }^{58}$. Empero la mejor demostración del éxito norteamericano vendría de la mano de los medios internacionales, contrastado en el moderado triunfalismo de sus diarios y en un periodismo latinoamericano que, aun sin expectativas previas, no disimularía su frustración tras el desenlace del Congreso ${ }^{59}$.

\section{Conclusiones}

La clausura de la reunión habanera abriría nuevamente el debate mediático sobre la naturaleza de las relaciones interamericanas. En apenas tres décadas -cuatro desde el primer congreso panamericano- los Estados latinoamericanos habían caído en un juego de poder en el que, conforme pasaba el tiempo, más difícil se hacía inhibirse de las directrices de Washington. Siquier aquellos países con mayor potencial y desarrollo, como Argentina, lograrían mantener cierto criterio propio, pero indudablemente condicionado de manera paulatina por una coyuntura que apuntaría a los Estados Unidos como potencia ya no continental sino mundial.

La conversión de la Doctrina Monroe en fundamento teórico del expansionismo haría que, lo que había sido una iniciativa loada en su origen por sus coetáneos, terminara generando todo un movimiento de oposición al sur de sus fronteras. Nicaragua, en realidad, no sería sino un paso más dentro de una larga carrera de intervenciones por parte de Estados Unidos en pro de imponer su hegemonía. Cuba, Haití, Panamá, República Dominicana, México, etc., sufrieron tales injerencias a lo largo de esos treinta años, ya fuese en su vertiente militar, comercial, diplomática o en un combinado de todas ellas. El problema radicaría en el empeño norteamericano por presentar tales intrusiones como un derecho legítimo; o, dicho de otro modo, en el intento de hacer presentable cara a la opinión pública internacional -sin dejar de lado a la propia- lo que no sería sino un claro ejercicio de despotismo.

La consecución de tal objetivo exigiría la anuencia, cuando no la complicidad, de los gobiernos de aquellos países en los que había inversiones o intereses estadounidenses. Una colaboración no siempre precisada de amenazas ya que, con frecuencia, la presencia de compañías norteamericanas en dichos territorios condicionaría sus economías hasta un extremo que los grupos de poder locales acabarían empleándose para dichas corporaciones o bien formando parte de sus mecanismos de control. Fue así que muchos de estos ejecutivos terminarían haciendo suyos los objetivos de estas empresas, dotando irresponsablemente a éstas de un influjo tal que, con los años, las llevaría a convertirse en un actor político determinante en el devenir de la región.

El caso nicaragüense aunaría muchos de los factores señalados. A la salida forzada de un gobierno, el de Zelaya, poco predispuesto a plegarse a las directrices de

solidaridad americana más valiera que la reunión comentada no se hubiera celebrado". La Libertad, año X, n 2470, 19-II-1928, 1.

58 "Cualesquiera que hayan sido los esfuerzos para eludir la toma directamente en consideración de los sucesos de Nicaragua y la política intervencionista de los Estados Unidos, aquí ha estado la piedra de toque del panamericanismo durante la Conferencia [ ...] La Conferencia se inició dentro de una atmósfera de protesta contra los Estados Unidos. En esta protesta no han dado el tono las Repúblicas de quien más se esperaba". El Sol, año XII, nº 3291, 19- II-1928, 1.

59 Respecto a los medios mexicanos: "Es unánime la opinión de todos los periódicos al considerar que ha sido un fracaso ruidoso, y señalan el hecho de que las pequeñas naciones no han recibido ninguna satisfacción. Solamente ha triunfado la diplomacia de los Estados Unidos". La Voz, año IX, nº 2291, 23-II-1928, 5. 
Washington le sucedió un periodo de estabilidad política determinado, sin ambages, por la presencia de fuerzas militares estadounidenses. Cierto es que Nicaragua no fue el único país en el que los marines se instarían de manera prolongada, pero en el caso nicaragüense la evolución de los acontecimientos probaría la absoluta dependencia de los nuevos mandatarios respecto a las fuerzas extranjeras. Tan solo su presencia garantizó la estabilidad de los gobiernos conservadores; y tan solo con hombres de su elección -el más recurrido, Adolfo Díaz- fue que los intereses norteamericanos se sintieron tranquilos. Del mismo modo, Nicaragua también podría considerarse un paradigma en cuanto al sentido de la supremacía practicado por los Estados Unidos o a la naturaleza de las críticas y apologías inspiradas en su ejercicio del poder. Una dinámica que, a rebufo de su predominio, permitiría a Washington justificar sus acciones en los foros panamericanos, con el apoyo de las delegaciones afines, en una clara ostentación de titerismo político ${ }^{60}$.

Con tales precedentes a nadie sorprenderían las manifestaciones de resignación, desencanto y frustración expresadas por una prensa e intelectualidad iberoamericanas expectantes en los prolegómenos de la reunión y crispadas tras su clausura. Unas manifestaciones que, en el caso español, serían semejantes en periódicos ideológicamente discrepantes, iluminando un punto de encuentro a no desdeñar en el análisis de un contexto políticamente complejo. Y una clausura que, en su falta de resultados, constataría nuevamente el predominio diplomático estadounidense y la división del bloque latinoamericano.

\section{Referencias bibliográficas}

Andrés García, Manuel. "De la "Patria Grande" a la "Madre Patria": Manuel Ugarte y el hispanoamericanismo español (1900-1930)". Revista de Indias, vol. 74, ${ }^{\circ}$ 261 (2014), 591-622. DOI: http://dx.doi.org/10.3989/revindias.2014.020

Arenal, Celestino del. La política exterior de España hacia Iberoamérica. Madrid: Editorial Complutense, 1994.

Bethell, Leslie (ed.). América Latina: Economía y Sociedad, c. 1870-1930. Barcelona: Crítica, 1991.

Butler, Smedley D. "America's Armed Forces: 2. 'In Time of Peace': The Army". Common Sense, vol. 4, no 11 (1935), 8-12. Disponible en https://msuweb.montclair.edu/ furrg/Vietnam/butler.pdf.

Castro Peña, Yeni. El mito Roosevelt para América Latina (1901-1909). Quito: Abya Yala - UASB, 2007.

Cisneros, Andrés - Escudé, Carlos. Historia de las Relaciones Exteriores de la República Argentina. Buenos Aires: GEL, 2000. Disponible en www.argentina-rree. com/historia.htm.

60 La Habana fue testigo de ello cuando, en el debate final que constató el desacuerdo sobre el principio de no intervención, Hughes se permitió sacar a colación la tan eludida cuestión nicaragüense en los siguientes términos: "En tiempos recientes mucho se ha dicho acerca de Nicaragua. Allí se sienta el Ministro de Relaciones Exteriores de Nicaragua, delegado de su país a esta Conferencia. Él puede hablaros la situación de Nicaragua; él puede deciros que no deseamos sino la independencia y la paz de su país y que estamos allí simplemente con el objeto de ayudarles a celebrar unas elecciones libres, de manera que puedan tener un gobierno soberano e independiente". Diario de la VI Conferencia Internacional Americana, no 35, 19-II-1928, 536-537. 
Dyer, Thomas G. Theodore Roosevelt and the Idea of Race. Baton Rouge - London: Louisiana State University Press, 1992.

Gracia Pérez, Felipe. Hijos de la Madre Patria. El hispanoamericanismo en la construcción de la identidad nacional colombiana durante la Regeneración (18781900). Zaragoza: Institución Fernando el Católico (CSIC), 2011. Disponible en http://ifc.dpz.es/recursos/publicaciones/31/20/ ebook.pdf.

Granados García, Aimer. Debates sobre España: el hispanoamericanismo en México a fines del siglo XIX. México DF: El Colegio de México - Universidad Autónoma Metropolitana-Xochimilco, 2005.

Jeffers, H. Paul (ed.). The Bully Pulpit. A Teddy Roosevelt Book of Quotations. Dallas: Taylor Publishing Company, 1998.

Kramer, Paul A. The Blood of Government: Race, Empire, the United States \& the Philippines. Chapel Hill: University of North Caroline Press, 2006.

Martí i Puig, Salvador. Tiranías, Rebeliones y Democracia. Itinerarios políticos en América Central. Barcelona: Bellaterra, 2004.

Maya Sotomayor, Teresa. "Estados Unidos y el panamericanismo: el caso de la I Conferencia Internacional Americana (1889-1890)". Historia Mexicana, vol. 45, $n^{\circ} 4$ (1996): 759-781. Disponible en www.jstor.org/stable/25139019.

Pereira Castañares, Juan Carlos. "Primo de Rivera y la diplomacia española en Hispanoamérica: El instrumento de un objetivo". Quinto Centenario, no 10 (1986), 131-156.

Pereira Castañares, Juan Carlos (coord.). La política exterior de España (18002003): historia, condicionantes y escenarios. Barcelona: Ariel, 2009.

Pereira Castañares, Juan Carlos - Cervantes Conejo, Ángel. Las relaciones diplomáticas entre España y América. Madrid: Mapfre, 1992.

Polak, Federico Gabriel. Un viejo diccionario español. La tontería del desarrollo argentino. Buenos Aires: Corregidor, 2005.

Quijano, Carlos. Nicaragua, ensayo sobre el imperialismo de los Estados Unidos, 1909-1927. Managua: Vanguardia, 1987.

Rodríguez Díaz, María del Rosario. Elihu Root y la política estadounidense en América Latina y el Caribe, 1899-1908. Morelia: Instituto de Investigaciones Históricas, UMSNH, 2006.

Ryan, David. U.S. Foreign Policy in World History (The New International History). London - New York: Routledge, 2000.

Selser, Gregorio. Sandino, General de Hombres Libres. Buenos Aires: Abril, 1984.

- Cronología de las intervenciones extranjeras en América Latina, 1776-1848, tomo I. México DF.: UNAM, 1994.

- Cronología de las intervenciones extranjeras en América Latina, 1849-1898, tomo II. México DF.: UNAM, 1997.

- Cronología de las intervenciones extranjeras en América Latina, 1899-1945, tomo III. México DF.: UNAM, 2001.

Sepúlveda Muñoz, Isidro. El sueño de la Madre Patria. Hispanoamericanismo y nacionalismo. Madrid: Marcial Pons Historia, 2005.

Smith, Robert Freeman. "América Latina, los Estados Unidos y las potencias europeas, 1830-1930". En América Latina: Economía y Sociedad, c. 1870-1930, editado por Bethell, Leslie. Barcelona: Crítica, 1991, 73-105.

Torres Rivas, Edelberto. Interpretación del Desarrollo Social Centroamericano. Santiago de Chile: PLA - América Nueva, 1969. 
U.S. Government (ed.). Minutes of the International American Conference. Actas de la Conferencia Internacional Americana. Washington: Govt. Print. Off., 1890. Disponible en https://archive.org/details/minutesofinterna00inte. 